\section{Commentary: Rheumatic valve surgery in emerging countries: New insights for an old disease}

\author{
Jean Porterie, MD, \\ Dimitri Kalavrouziotis, MD, FRCSC, and \\ Siamak Mohammadi, MD, FRCSC
}

Due to socioeconomic factors, scarce health care infrastructure, a general lack of preventative policies, and an extremely high rate of population growth, rheumatic heart disease (RHD) has a high health-related burden in subSaharan Africa. ${ }^{1}$ Decision-making is challenging regarding surgical options, including valve repair, valve replacement, and type of prosthesis (mechanical vs biological). There is a paucity of data on the benefits and drawbacks of alternative surgical approaches and an absence of reliable long-term data on clinical outcomes in this unique population with severe disease often involving multiple valves. Many humanitarian efforts deployed in underserved African populations have brought to light some broad challenges, including selection and monitoring of patients, material availability, training of local teams and transmission of knowledge, as well as the global reorganization of healthcare systems.

In this issue of the Journal, Tamirat and colleagues ${ }^{2}$ evaluated the outcomes of aortic and mitral valve surgery for RHD in 240 consecutive patients in a single Ethiopian center between 2009 and 2017 in the context of 22 international humanitarian missions. The majority were young female patients (mean age 19 years) which underwent valve replacement (any valve position) either by a mechanical $(\mathrm{n}=90)$ or biological $(\mathrm{n}=58)$ prosthesis; $\mathrm{n}=92$ underwent valve repair, with an overall operative mortality of $2.1 \%$. After a median follow-up of 2.3 years, 11 additional patients died and almost a quarter of them $(\mathrm{n}=55)$ experienced at least 1 major adverse valve-related event

From the Division of Cardiac Surgery, Quebec Heart and Lung Institute, Laval University, Quebec City, Quebec, Canada.

Disclosures: Authors have nothing to disclose with regard to commercial support.

Received for publication March 29, 2020; revisions received March 29, 2020; accepted for publication March 30, 2020; available ahead of print April 11, 2020.

Address for reprints: Siamak Mohammadi, MD, FRCSC, Department of Cardiac Surgery, Quebec Heart and Lung Institute, 2725 chemin Sainte-Foy, Quebec City, Quebec G1V 4G5, Canada (E-mail: siamak.mohammadi@fmed.ulaval.ca).

J Thorac Cardiovasc Surg 2021;162:1728-9

$0022-5223 / \$ 36.00$

Copyright (c) 2020 by The American Association for Thoracic Surgery

https://doi.org/10.1016/j.jtcvs.2020.03.126

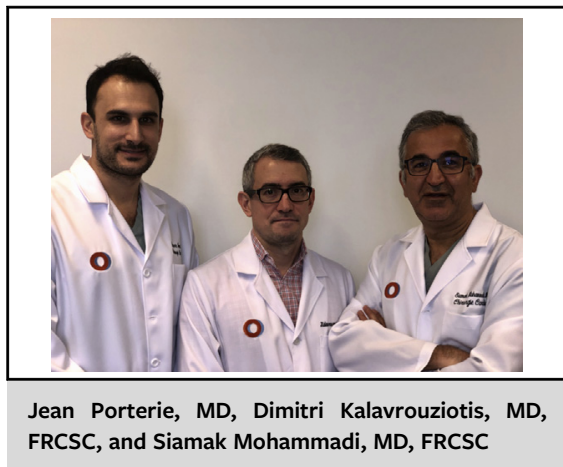

\section{CENTRAL MESSAGE \\ Rheumatic valvular disease is \\ prevalent in emerging countries, with no ideal surgical option. \\ Preventative measures, enhancement of local health \\ care capabilities, and rigorous \\ follow-up of these patients are \\ paramount.}

(MAVRE). The authors demonstrated that the risk of death and MAVRE were significantly greater in the bioprosthetic group than in the mechanical group (hazard ratio, 8.82; $95 \%$ confidence interval, 1.64-47.39 and hazard ratio, $2.71 ; 95 \%$ confidence interval, 1.13-6.49, respectively), mainly due to structural valve dysfunction (SVD), whereas there was no significant difference between repair and mechanical prosthesis groups. The authors concluded that despite acceptable perioperative outcomes, left-sided valve surgery for RHD in sub-Saharan Africa was associated with a high incidence of MAVRE at follow-up, and bioprosthetic valves have poorer outcomes in this patient population, mainly due to the early SVD.

The authors should be congratulated for their repeated commitment to humanitarian missions and for their dedication to the training of local medicosurgical teams for the management of prevalent but complex valvular diseases in sub-Saharan Africa in the setting of suboptimal systems of care ${ }^{3}$ and little to no meaningful data collection and outcomes analysis. However, the results of the present study should be analyzed in light of some considerations. First, several methodologic limitations may have biased the conclusions of the authors: (1) confounding by indication may have been present, as non-rheumatic pathologies such as endocarditis may have impacted both the prosthetic choice 
and outcomes; (2) the analysis did not take into account the location (aortic vs mitral) or the type and the model of implanted valves, which are known to significantly impact the risk of SVD/thromboembolic events/risks associated with anticoagulation $^{4,5}$; (3) selection of mechanical versus biological prostheses was likely influenced by several factors that were not accounted for in the analysis, such as socioeconomic context and the likelihood of downstream access to care; (4) there were significant disparities in the treatment of non-prosthesis-related anticoagulation (eg, atrial fibrillation) between the 3 surgical strategies; and (5) in a very young population, the mean follow-up was relatively short, precluding accurate analysis of long-term outcomes.

The results of the study by Tamirat and colleagues ${ }^{2}$ are consistent with previous reports showing greater SVD and mortality rates with bioprosthetic compared with mechanical valves in young patients. ${ }^{6,7}$ However, attributing SVD as the sole reason for the dismal outcomes of patients with bioprosthetic valves is problematic. It is well known that underprivileged areas have limited on-shelf inventory at the time of surgery, and thus the selection of an appropriate prosthesis for the individual patient may not have relied on traditionally accepted patient, aortic root, and annular parameters. Furthermore, the median implanted prosthesis size was lower in the bioprosthetic group than in the mechanical group for both the aortic and mitral positions, which raises questions given the significantly younger age (and higher growth potential) of patients receiving biosprostheses, by an average of 5 years $(18 \pm 6$ vs $23 \pm 8$ years, $P<.001)$. A major additional drawback is the unavailability of postoperative and late echocardiographic data, which are critical adjuncts to a precise and accurate SVD diagnosis. ${ }^{8}$

It is intuitive that the management of the patient with a mechanical prosthesis is complicated in regions with a low density of medical facilities and variable access to care, and inconsistent patient education and compliance with oral anticoagulation. In the study by Tamirat and colleagues, ${ }^{2}$ most of late strokes and major bleeding events were observed in the mechanical prosthesis group. Poor access to health care negatively impacts prevention, diagnosis, and management of these serious complications. The desire for future pregnancy in this young cohort also introduces an added element of complexity.

Despite the well-known advantages of valve repair over replacement for a variety of mitral valve pathologies, valve repair is less reproducible in rheumatic disease. ${ }^{9}$ Almost one third of the repair group experienced MAVRE, and 2 patients required reintervention. These results were not adjusted for individual surgeon expertise, and the context of a humanitarian mission of limited temporal duration, coupled with inconsistent local echocardiographic skills for accurate preoperative assessment, may keep the learning curve of complex mitral valve repair in this setting insurmountable. Determining the ideal prosthesis type (mechanical vs biological) for RHD is all-the-more urgent in this setting.

Despite the aforementioned considerations, and keeping in mind the extremely young and sick population with RHD, overall outcomes were encouraging in this series. By their invaluable experience, the authors demonstrated that in areas of limited medical resources, drawbacks related to the different surgical options remain largely similar as in developed countries, but follow-up is pivotal before one strategy can be said to be more effective than another. In this context, the development of robust health care systems and the improvement of education and prevention in these populations should be the major challenges in the coming years. Beyond their immediate clinical impact and prosthetic choice, the international humanitarian missions have a crucial role in the enhancement of local teams with expertise in the prevention, diagnosis, management, and follow-up of cardiovascular diseases.

\section{References}

1. The 2015 Revision of the UN's World Population Projections. Popul Dev Rev. 2015;41:557-61.

2. Tamirat S, Mazine A, Stevens LM, Agwar F, Dejene K, Berdu M, et al. Contemprory outcomes of aortic and mitral valve surgery for rheumatic heart disease in Sub-Saharan Africa. J Thorac Cardiovasc Surg. 2021;162:1714-25.e2.

3. Watkins DA, Johnson CO, Colquhoun SM, Karthikeyan G, Beaton A, Bukhman G, et al. Global, regional, and national burden of rheumatic heart disease, 1990-2015. N Engl J Med. 2017;377:713-22.

4. Falk V, Baumgartner H, Bax JJ, De Bonis M, Hamm C, Holm PJ, et al. 2017 ESC EACTS Guidelines for the management of valvular heart disease. Eur J Cardiothorac Surg. 2017;52:616-64.

5. Nishimura RA, Otto CM, Bonow RO, Carabello BA, Erwin JP, Fleisher LA, et al 2017 AHA/ACC Focused Update of the 2014 AHA/ACC Guideline for the management of Patients with valvular heart disease: a report of the American College of Cardiology/American Heart Association Task Force on Clinical Practice Guidelines. Circulation. 2017;135:e1159-95.

6. Goldstone AB, Chiu P, Baiocchi M, Lingala B, Patrick WL, Fischbein MP, et al Mechanical or biologic prostheses for aortic-valve and mitral-valve replacement. N Engl J Med. 2017;377:1847-57.

7. Rusingiza EK, El-Khatib Z, Hedt-Gauthier B, Ngoga G, Dusabeyezu S, Tapela N, et al. Outcomes for patients with rheumatic heart disease after cardiac surgery followed at rural district hospitals in Rwanda. Heart. 2018;104:1707-13.

8. Akins CW, Miller DC, Turina MI, Kouchoukos NT, Blackstone EH, Grunkemeier GL, et al. Guidelines for reporting mortality and morbidity after cardiac valve interventions. J Thorac Cardiovasc Surg. 2008;135:732-8.

9. LaPar DJ, Ailawadi G, Isbell JM, Crosby IK, Kern JA, Rich JB, et al. Mitral valve repair rates correlate with surgeon and institutional experience. J Thorac Cardiovasc Surg. 2014;148:995-1004. 